\title{
Analysis of the Causes of Vehicle Accidents in Poland in 2009-2019
}

\author{
Emilia Szumska ${ }^{1}$, Damian Frej $^{1^{*}}$ and Paweł Grabski ${ }^{1}$ \\ ${ }^{1}$ Department of Automotive Engineering and Transport, Kielce University of Technology, Kielce, \\ Poland; Email:eszumska@tu.kielce.pl, frejdamian@gmail.com,pgrabski@tu.kielce.pl
}

*Corresponding Author: Emilia Szumska

Received: 13 October 2020; Revised: 23 October 2020; Accepted: 26 October 2020; Published: 30 November 2020

\begin{abstract}
The article presents the general characteristics of road transport safety in Poland over the years 2009-2019. The key objective of this study was to investigate the main factors of road accidents in Poland. Up till now, the number of road accidents has been analysed in detail on the basis of data on collisions from rear, side and frontal perspective. Moreover, in the article, statistics regarding the number of perpetrators of accidents by gender and age are summarized, as well as dynamics aspects of changes related to new passenger vehicles and trucks in Poland in 2009-2019 are indicated. As a result, the intensity of rear collisions rather than frontal collisions is apparent. Hence, an inconspicuous rear collision by not braking a speeding vehicle carries a risk of the upper cervical spine.
\end{abstract}

Keywords: Road accidents, collisions, road safety, passenger vehicle

\section{Introduction}

According to World Health Organization, approximately 1.35 million people die each year as a result of road traffic crashes [1]. Almost 3.700 people are killed daily all over the world in road traffic crashes involving pedestrian or different transport mode such as vehicles, buses, motorcycles, bicycles, trucks. More than half of those killed are pedestrians, motorcyclists, and cyclists [2]. Despite the advanced vehicle safety systems, the traffic accidents are still bringing the high number of fatalities and injuries. The main reasons of traffic accidents could be divided in three risk factors, such as accommodating human error, technical condition of vehicles, and road infrastructure [3].

In research [4], the authors identified risk factors before the crash, during the crash and after the crash in relation to the person, vehicle and road infrastructure. For the pre-crash phase, it is necessary to select all countermeasures that prevent the crash from occurring. The crash phase is associated with countermeasures that prevent an injury from occurring or reduce its severity if it 
does occur. Finally, the post-crash phase involves all activities that reduce the adverse outcome of the crash after it has occurred. The separated factors associated with a crash allow recognizing and analysing countermeasures.

Table 1 Accident risk factors. Source: [4]

\begin{tabular}{|c|c|c|c|c|}
\hline & Phase & Human & $\begin{array}{l}\text { Vehicles and } \\
\text { equipment }\end{array}$ & Environment \\
\hline $\begin{array}{l}\text { Pre- } \\
\text { crash }\end{array}$ & Crash prevention & $\begin{array}{l}\text { Information } \\
\text { Attitude } \\
\text { Impairment } \\
\text { Police } \\
\text { enforcement }\end{array}$ & $\begin{array}{c}\text { Roadworthiness } \\
\text { Lighting } \\
\text { Braking } \\
\text { Handling } \\
\text { Speed management }\end{array}$ & $\begin{array}{l}\text { Road design and layout } \\
\text { Speed limits } \\
\text { Pedestrian facilities }\end{array}$ \\
\hline crash & $\begin{array}{l}\text { Injury prevention } \\
\text { during the crash }\end{array}$ & $\begin{array}{l}\text { Use of restraints } \\
\text { Impairment }\end{array}$ & $\begin{array}{c}\text { Occupant restraints } \\
\text { Other safety devices } \\
\text { Crash protective } \\
\text { design }\end{array}$ & $\begin{array}{l}\text { Crash-protective } \\
\text { roadside objects }\end{array}$ \\
\hline $\begin{array}{l}\text { Post- } \\
\text { crash }\end{array}$ & Life sustaining & $\begin{array}{c}\text { First-aid skill } \\
\text { Access to medics }\end{array}$ & $\begin{array}{c}\text { Ease of access } \\
\text { Fire risk } \\
\end{array}$ & $\begin{array}{c}\text { Rescue facilities } \\
\text { Congestion }\end{array}$ \\
\hline
\end{tabular}

The risk factors dependent on driver include speeding, driving under the influence of alcohol and other psychoactive substances, driving without motorcycle helmets, unfastened seat-belts, children transported without child restraints, driver psychological attitude, and distractions during driving (e.g. using mobiles). The driver's experience, skills, observation capabilities, and ability to recognize potential hazards allow to avoid possible traffic incidents. Most of the studied risk factors related to human behaviour has been examined in the literature [5,6]. Authors of the paper [7] distinguished three types of behaviour that increase the risks of causing an accident: errors, lapses and violations. Accidents may be caused by perception errors and misjudgement of the driving conditions, for instance hard braking on slippery surface, high speed cornering, or sudden lane change. The misperception may occur due to incomplete processing, neglect of available information or due to receiving incorrect information. They have an impact on driver decisionmaking, risk tolerance, and behaviour. The errors in perception resulting implications for road safety $[8,9]$.

Lapses can refer to attention and memory failures, such as hitting something when reversing that one had not seen or attempting to drive away from traffic lights in the wrong gear. Lapses are commonly committed by unexperienced drivers $[10,11]$ or senior drivers $[12,13]$. Violations refer to deviations from formal prohibitions and mandatory rules for road users defined in highway code. Examples are speeding or overtaking on the inside. As proved by various research [14-16] violations appeared to be most strongly related to crashes. There may also found studies devoted to the physical or mental factors, which have an impact on driver style causing unusual driving behavior. Particular examples can be found in the literature [17-19] among the others. 
The vehicle-related risks include the technical condition of main vehicle systems, such as brake system, steering system, lighting system, and safety devices. Correct operation of vehicle systems reduces the traffic safety hazards.

The other risk factor is road infrastructure. Road design and road layout should be highly complex. The interactions between road users requires introduction of appropriate traffic organization, adjusting footpaths, cycling lanes, safe crossing points, and other traffic calming measures to reducing the risk of injury among these road users. According to [20,21] population density is associated with the accidents frequency. The inhabitants of cities are far more exposed to road crashes than population of rural areas. The urban traffic conditions consist in low speed driving, while inter-urban traffic demands higher speeds and continuous flows. The domestic and international roads register higher fatality rates than pure urban roads. This kind of roads is designed exclusively for high-speed vehicular traffic. Study [22] confirmed that traffic casualties are likely to happen on higher speed roads and motorways but not during traffic congestion. The results presented in [23] exhibited that the risk in poor weather and road conditions was higher on motorways compared to two-lane and multiple-lane roads even though the overall risk was low on motorways. According to research [24] the most significant contributors to road accidents at hazardous locations are: average running speed, posted speed, maximum and average degree of horizontal curves, number of vertical curves, median width, type of road surface, time of a day, number of vehicles per hour, number of pedestrian crossing streets and percentage of heavy duty vehicles.

The aim of this study was to investigate the main factors of road accidents in Poland. Presented analysis shows the crashes involving drivers of varying ages and gender, time of a day, and seasons. This paper also shows the number of injuries and fatalities by a type of road traffic collisions.

\section{Number of Road Accidents in Poland in 2009-2019}

Road accidents are a serious problem for modern society, which results from the costs of treating accident victims as well as economic and property costs. Undoubtedly, the frequency of accidents is related to the skills of drivers and the modern lifestyle in which more and more people travel [2527]. In addition, it should be noted that the vehicles of that time were equipped with various types of modern gadgets, e.g. a screen that allows you to watch movies. They are designed to improve the journey, but they can also distract the driver with a consequent road accident [28]. It should be noted that not only the internal environment of the vehicle is able to distract the driver. Billboards, advertising slogans, large screens, illuminated signs, all those elements that force the driver's attention may cause the driver's inattention, and thus the cause of a road accident [29]. 
In Poland, the total length of the public road network is over 420,000 km [30]. However, the total number of Polish citizens reaches 38 million There are registered vehicles in Poland every year. The dynamics of changes in registered vehicles in Poland in 2009-2019 is shown in Figure 1. According to the Police statistics, the average value of the increase in registered vehicles over 10 years is $3.66 \%$. The number of registered passenger vehicles in 2019 was $23,874.5$ thousand, while in 2009 - 16,494.7 thousand. Thus, in 10 years the number of registered vehicles increased by $31 \%$ $[29,31]$.

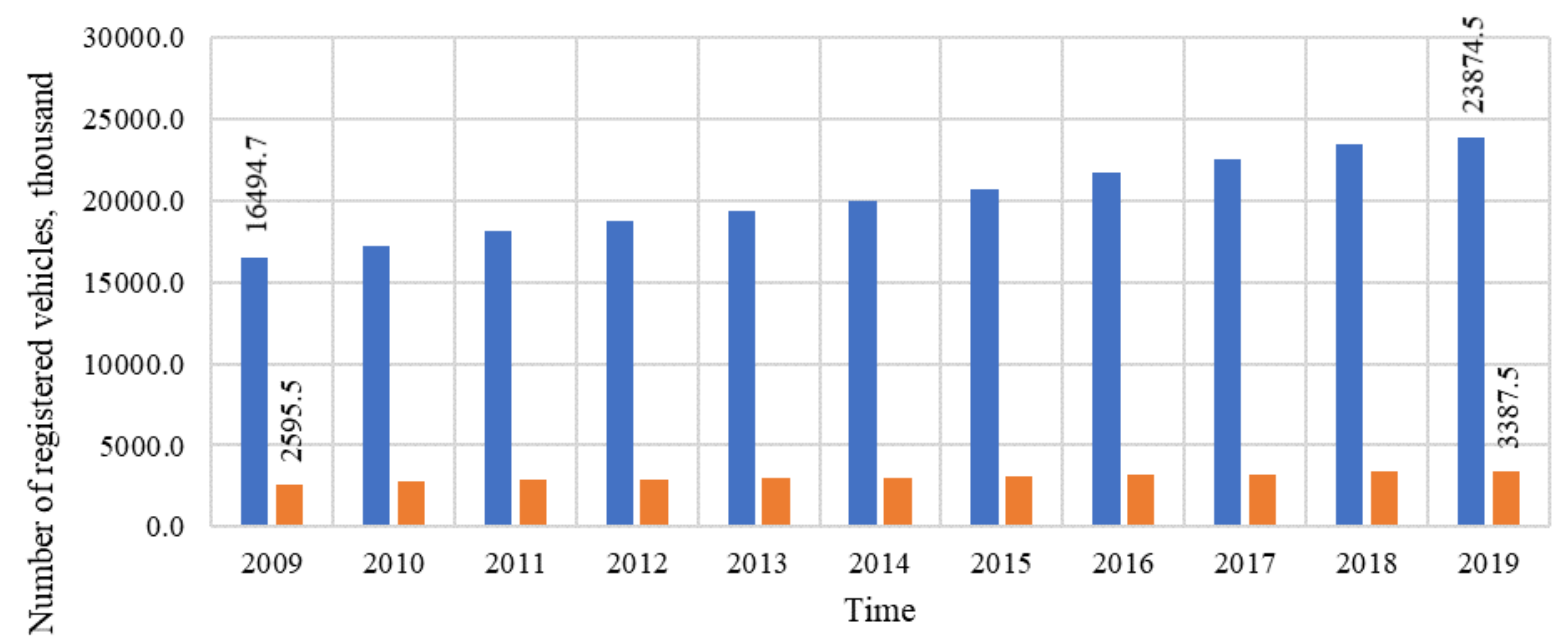

- Passenger Vehicle $\quad$ Trucks

Fig. 1 The number of registered motor vehicles in Poland and the dynamics of changes in 20092019. Source: authors

Based on data from the Central Statistical Office (GUS) for 2019, it is stated that the largest number of passenger vehicles on the roads in Poland is in the age range from 10 to 14 years (26\% of all passenger vehicles) and from 3 to 5 years (22, 8\% of all passenger vehicles) [32].

Poles are increasingly using passenger vehicles. The research conducted by the Central Statistical Office in 2018 shows that the average daily mileage of a passenger vehicle is $37 \mathrm{~km}$, while the average time spent driving a vehicle is 30 to 60 minutes a day [33]. A passenger vehicle is undoubtedly an indispensable element of every person's life, it is what most people use to commute to work, go on vacation or go shopping. Public transport or rail transport modes are not as popular as passenger vehicle transport [29,34].

Road accidents have a very complex cause-effect structure, therefore they are classified as the main problems in the country. The annually high number of road accidents in Poland is not only the basis for the analysis of the current situation, but above all it is a warning for all road users and entities responsible for road safety. The annual reports of the Police show that the level of road traffic risk in Poland is too high compared to other EU Member States. Poland is one of those 
European Union countries with a large number of road casualties. The death rate as a result of road accidents per 1 million inhabitants is an indicator of safety used by the European Union. In Poland, this indicator in 2019 amounted to 77 deaths per million inhabitants, while for the entire European Union it was $51[30,33]$.

During the last 10 years, as many as 392,309 road accidents took place in Poland, as a result of which 37,364 people were killed and 479,198 were injured [29]. On average, 3,394 people die each year on Polish roads as a result of a vehicle accident [33]. In 2019, the number of accidents on Polish roads decreased by $4.4 \%$ and injuries by $5 \%$ compared to 2018 . Unfortunately, the number of fatalities as a result of a road accident increased by 1.6\%. From 2010 to 2019, there was a decrease in the number of vehicle accidents by $31 \%$ and a decrease in the number of fatalities by $36 \%$.

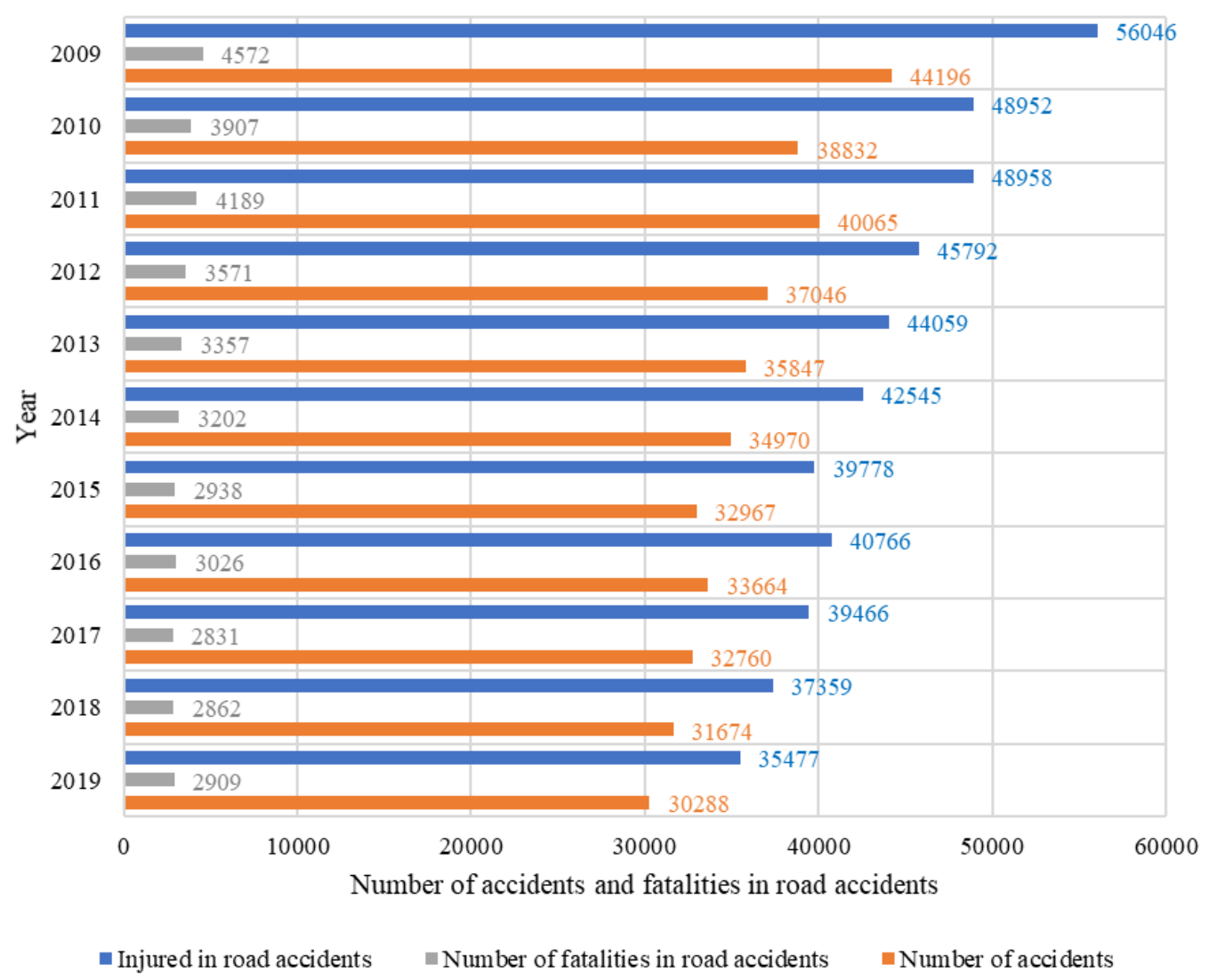

Fig. 2 Number of road accidents and the number of fatalities in Poland in 2009-2019. Source: authors

When analyzing the number of vehicle accidents, attention should be paid to individual regions of the country and the indicator of the number of vehicle accidents per 100,000 inhabitants (Fig. 3). Based on the data from police reports, it should be noted that in the past 10 years, the average number of vehicle accidents decreased by 37 per 100,000 inhabitants. The smallest decrease occurred in Wielkopolska and amounted to 5.8, while the highest decrease in the number of accidents per 100,000 inhabitants was 58.8 for the Łódzkie Voivodeship [29,33]. 


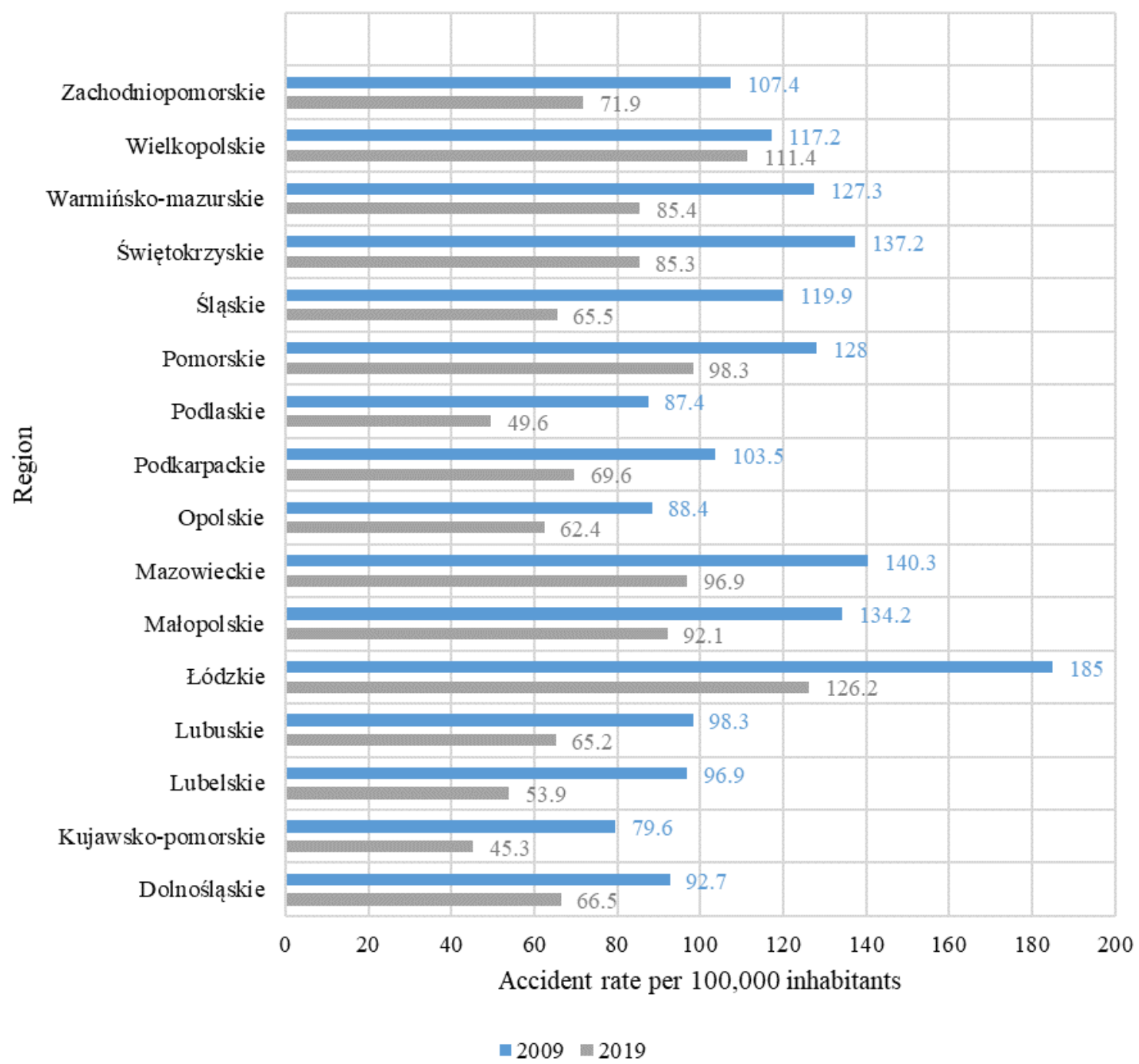

Fig. 3 Number of road accidents per 100,000 inhabitants in Poland in 2009 and 2019.

Source: authors

When analyzing vehicle accidents in Poland on the basis of the type of collision (Fig. 4), it should be noted that the number of side accidents is the most common form of vehicle accidents. Moreover, from 2009 to 2019, their number remains at an average of 10,000 per year. However, the number of front and rear collisions remains at the level of 4.5 thousand per year. It should be noted that deaths on Polish roads resulted from a collision (Fig. 5) [29]:

- Side - 6656 people,

- Frontal - 6,529 people,

- Rear - 2,172 people.

The years 2011-2019 show, that there were more rear collisions than frontal collisions (Fig. 4). Moreover, a rear collision in the period under review accounts for approximately $13 \%$ of all road accidents. Compared to frontal or side collisions, they are rarely fatal. However, many participants 
in this type of accident suffer severe damage. In the event of a rear-end collision, passengers and the driver are at risk of whiplash injuries. This type of collision most often occurs through $[29,35]$ :

- failure to maintain the correct distance from the vehicle driving in the same direction,

- excessive speed,

- lack of attention, e.g. when driving in a traffic jam,

- bad condition or failure of the brake system.

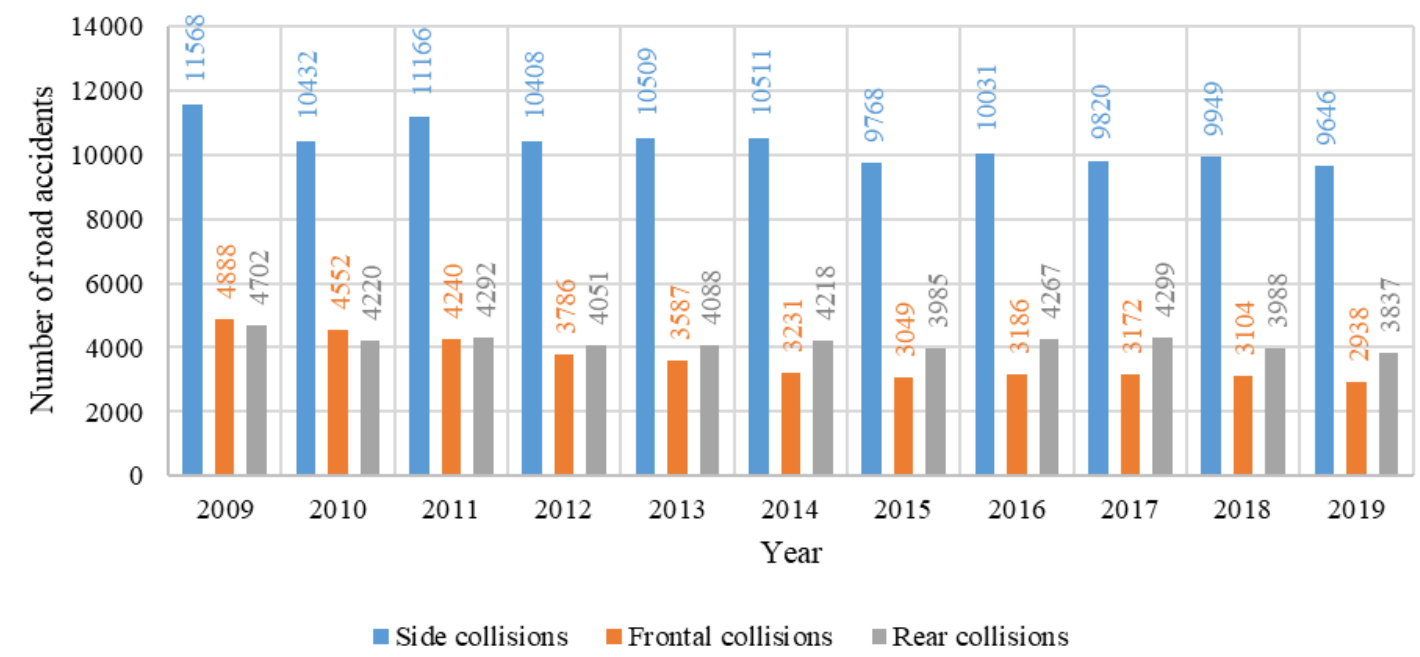

Fig. 4 Number of road accidents taking into account the division into side, front and rear collisions in the years 2009 - 2019. Source: authors

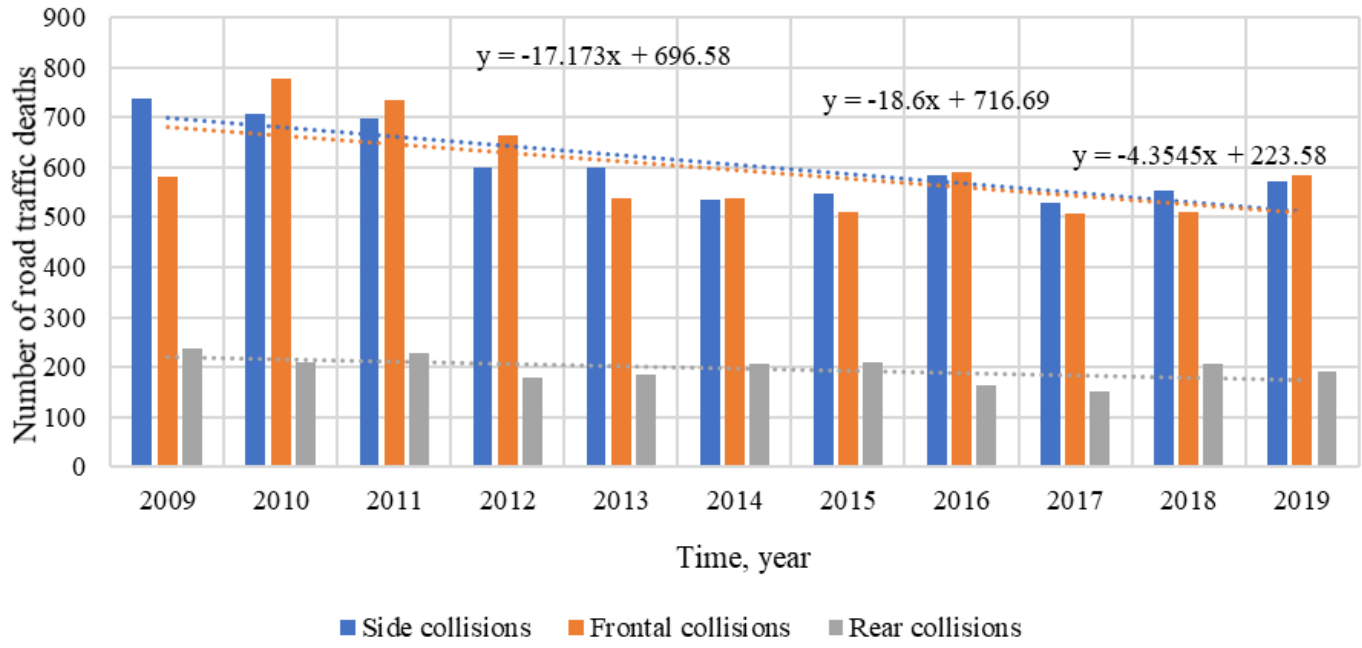

Fig. 5 Number of fatalities in road accidents in Poland, taking into account the division into side, front and rear collisions in the years 2009-2019. Source: authors 
The vehicle which is hit backwards accelerates sharply forwards. When the driver's seat and passenger's seat are hit, they move forward. In the initial phase, the head of the vehicle user moves forwards and then returns with greater force to the backrest of the vehicle seat [34]. This unnatural rapid movement of the neck in both directions can damage the cervical spine. Therefore, rear collisions are very problematic because at a relatively low impact velocity, cervical vertebrae may be ruptured and a person may die.

\section{Determinants of Vehicle Accidents in Poland}

The causes of road accidents vary widely, but their occurrence is related to variables such as gender and age of drivers. Figure 6 presents the characteristics of vehicle accidents in 2009-2019, where a decrease by $1.37 \%$ for men and $4.37 \%$ for women as drivers at fault of vehicle accidents in the period under review may be noticed. Every year in Poland, from 2009 to 2019, an average of 4\% of vehicle accidents perpetrators are not identified [30,33].

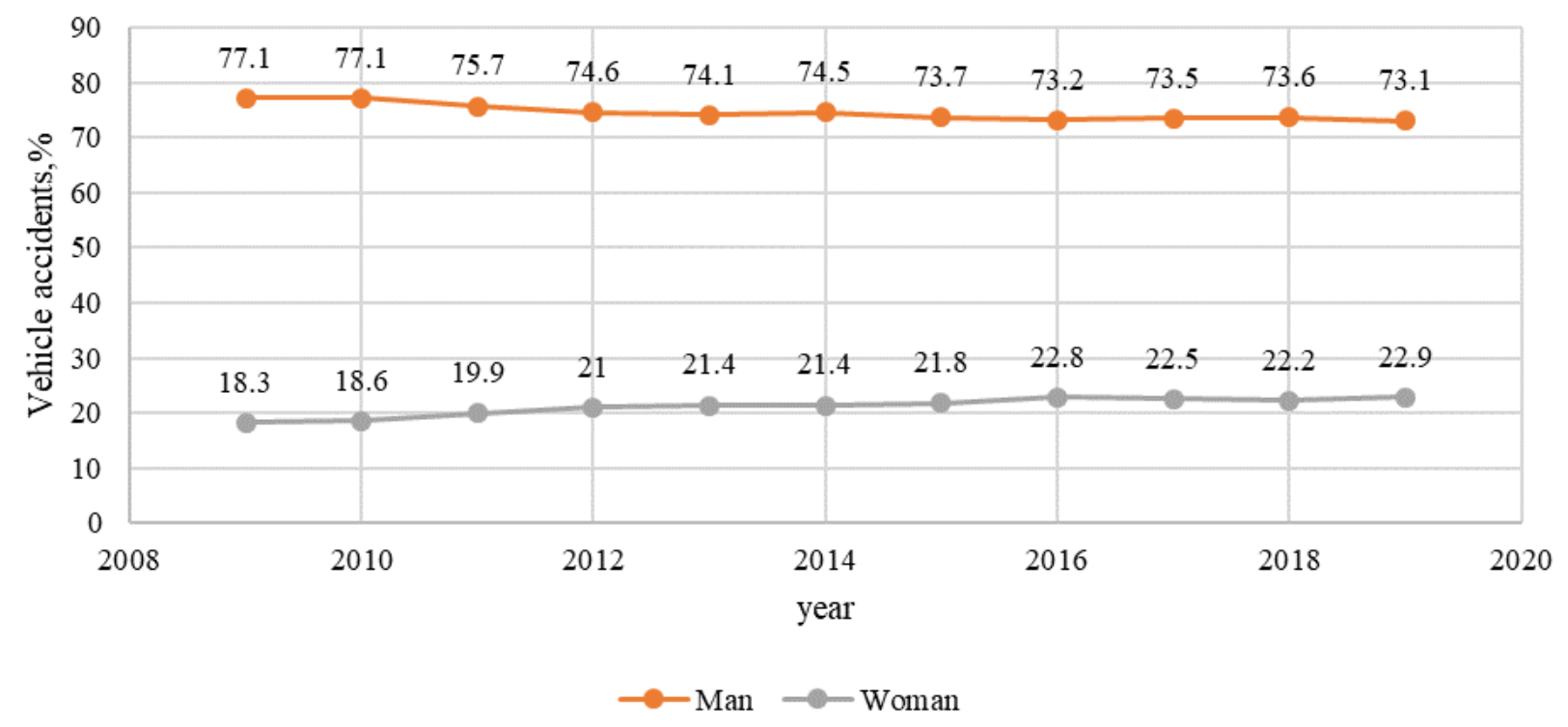

Fig. 6 Perpetrators of vehicle accidents, according to gender. Source: authors

Based on data from police reports from 2009 to 2019, it can be noted that the largest group of perpetrators of vehicle accidents in Poland are people from 25 to 39 years of age (fig. 7). On average, they account for $35 \%$ of all road accidents perpetrators. People from 18 to 24 years of age on average account for about $20 \%$ of accidents perpetrators $[29,33]$. 


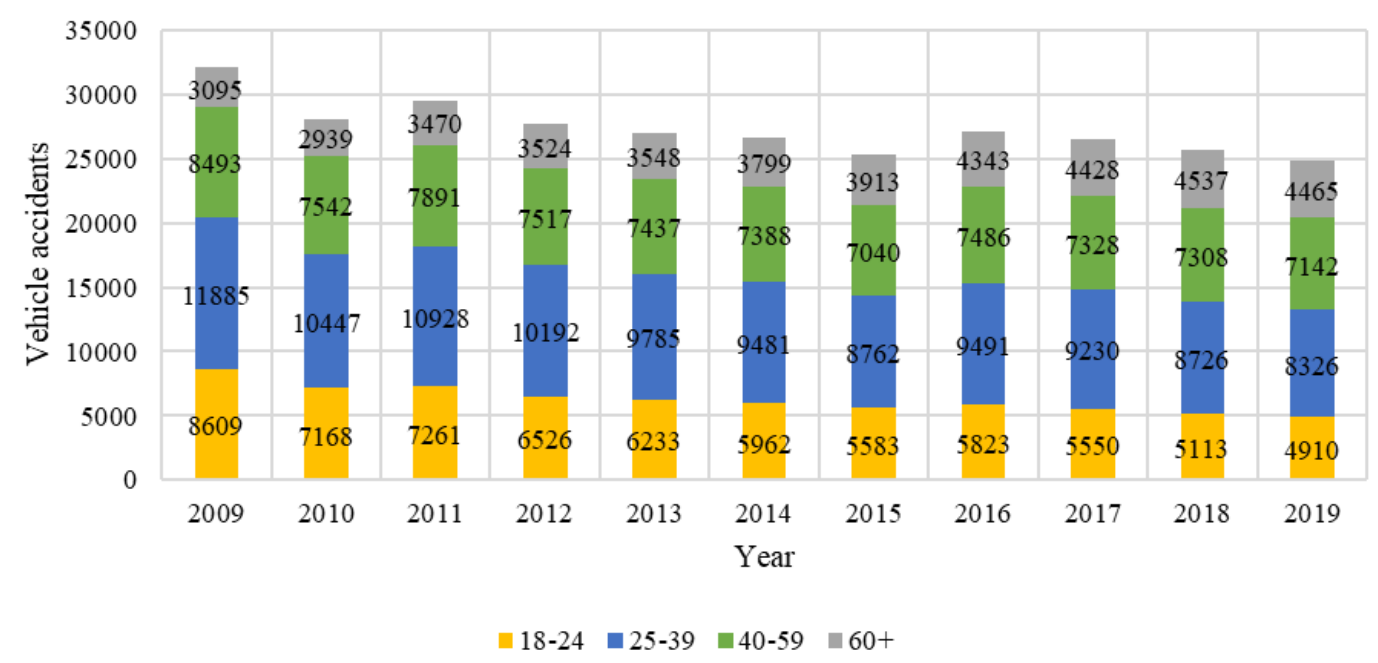

Fig. 7 Perpetrators of vehicle accidents, according to age. Source: authors

The most common causes of vehicle accidents in Poland include $[35,36]$ :

- failure to respect the right of way of the vehicle,

- maladjustment of speed to the prevailing road conditions,

- failure to give way to pedestrians at a pedestrian crossing,

- failure to maintain a safe distance between vehicles,

- pedestrian misbehavior, and incorrect vehicle overtaking.

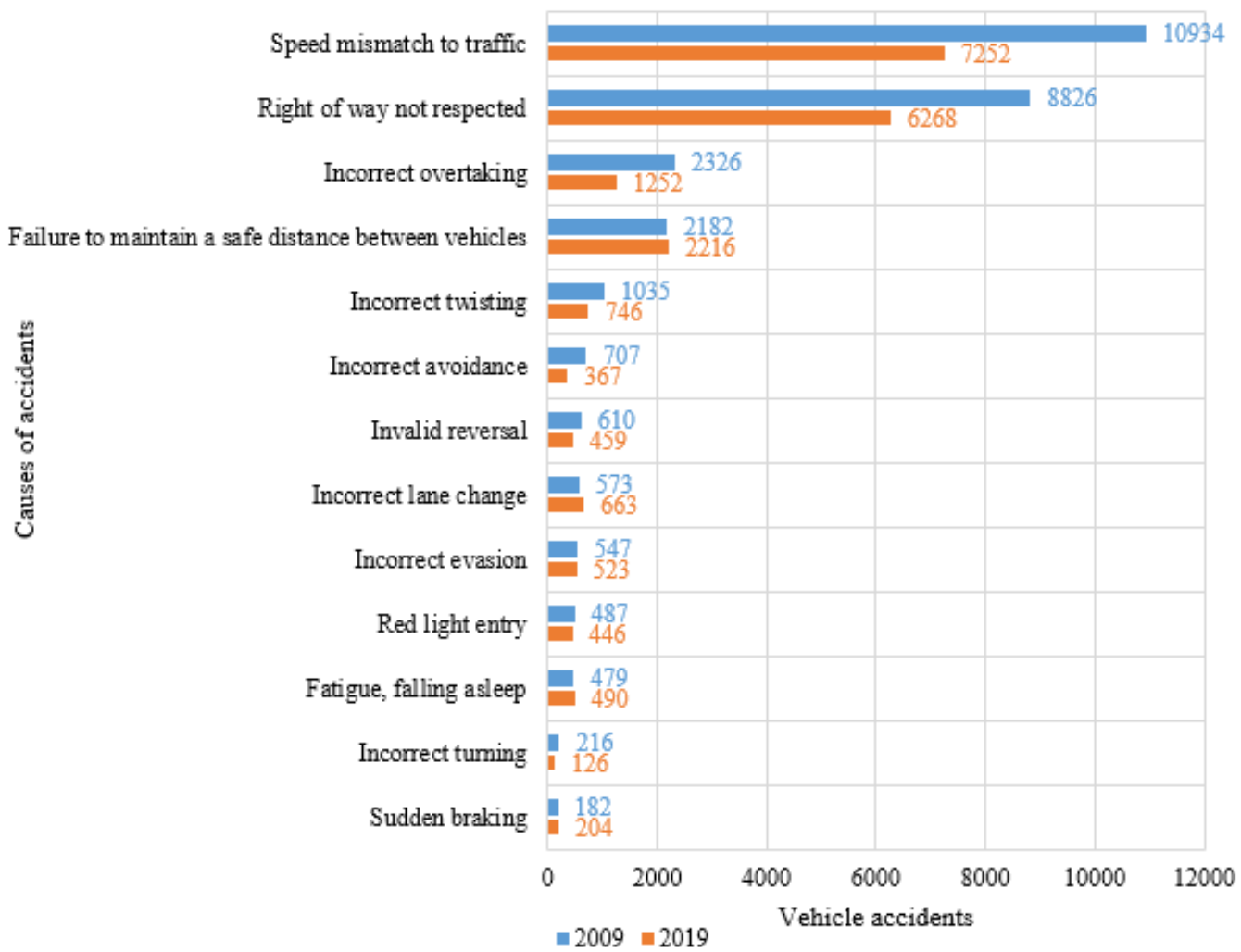

Fig.8 The most common causes of road accidents in Poland in 2009 and 2019. Source: authors 
Figure 8 presents the characteristics of the number of causes of road accidents in Poland in 2009 and 2019. It can be noticed that in case of reasons such as speed mismatch or failure to respect the right of way, there was a decrease by over $15 \%$. However, in the case of failure to adjust the safe distance between vehicles, it slightly increased in 2019 than in 2009 . That is confirmed by the fact that rear collisions have the lowest downward trend among all types of collisions.

\section{Conclusion}

The aim of this article was to present the road safety issues in Poland over the years 2009-2019, with a detailed consideration of the data on side, front and rear accidents, as well as the characteristics of perpetrators of road accidents in terms of gender and age of drivers. The analysis shows that the number of accidents in 2009-2019 decreased significantly. Moreover, the result shows a large downward trend in the case of side or frontal collisions. Rear collisions are a problematic type of road accidents, and they remain almost the same every year in Poland. The development of road infrastructure through the expansion of the network of motorways and expressways contributes to the reduction of the number of road accidents in terms of side and frontal collisions. Moving vehicles in one direction only increase the likelihood of rear-end collisions. In the years 2009-2019, 2,172 people died due to rear collisions on Polish roads. Therefore, it should be noted that an inconspicuous rear collision vehicle carries a high risk of damage to the upper cervical spine. Even at low speeds of $20 \mathrm{~km} / \mathrm{h}$, such a collision may cause irreversible health effects, leading to disability.

\section{References}

[1] WHO (2018). Global status report on road safety https://www.who.int/news-room/factsheets/detail/road-traffic-injuries.

[2] Jian, T., Zhi-qiang, L., Jian-feng, X. \& Hong-yu G. (2019). Cause Analysis and Countermeasures of fatal Traffic Accidents on Road Passenger Transportation Based on Typical Cases. In 5th International Conference on Transportation Information and Safety (ICTIS), Liverpool, United Kingdom (pp. 951-955). DOI: 10.1109/ICTIS.2019.8883569.

[3] Petridou, E. \& Moustaki, M. (2000). Human factors in the causation of road traffic crashes. European Journal of Epidemiology 16, 819-826.

[4] Haddon, Jr. W. (1980). Advances in the epidemiology of injuries as a basis for public policy. Public Health Report, DOI: 95:411-421.

[5] Steg, L. \& Brussel A. (2009, November). Accidents, aberrant behaviours, and speeding of young moped riders. Transportation Research Part F: Traffic Psychology and Behaviour 12(6), 503-511.

[6] Nowakowska, M. (2012). Road Traffic Accident Patterns A Conceptual Grouping Approachto Evaluate Crash Clusters. The Archives of Transport24(1).

[7] Reason, J., Manstead, A., Stradling, S., Baxter, J. \& Campbell, K. (1990). Errors and violations on the roads: A real distinction of ergonomics 33, 1315-1332. 
[8] Åberg, L., Afram, G. \& Nilsson M. (2005). Perception of other drivers' errors and violations and easiness of error detection. Psychology.

[9] Eboli, L., Mazzulla, G. \& Pungillo, G. (2017). Measuring the driver's perception error in the traffic accident risk evaluation. IET Intelligent Transport Systems 11.

[10] Girotto, E., Andrade, S.M., González, A.D. \& Mesas, A.E. (2016). Professional experience and traffic accidents/near-miss accidents among truck drivers. Accident Analysis \& Prevention95, Part A, 299-304,

[11] Reeja, S., \& Jayaraj, V.S. (2017). An embedded based approaches for accident analysis using event data recorder. In IEEE International Conference on Electrical, Instrumentation and Communication Engineering (ICEICE), Karur (pp. 1-5). DOI: 10.1109/ICEICE.2017.8191920.

[12] Clarke, D.D. \& Craig, P.W. \& Truman, B.T. (2006). Young driver accidents in the UK: The influence of age, experience, and time of day. Accident Analysis \& Prevention 38(5), 871878.

[13] Zhang, Z. (2010). Research on the taxi traffic accident and violation identification model. In: 2010 2nd International Asia Conference on Informatics in Control, Automation and Robotics (CAR 2010), Wuhan (pp. 533-536). DOI: 10.1109/CAR.2010.5456616.

[14] Poulter, D.R. \& Wann, J.P. (2013, August). Errors in motion processing amongst older drivers may increase accident risk. Accident Analysis \& Prevention 57, 150-156.

[15] Amin, S. (2020, February). Backpropagation - Artificial Neural Network (BP-ANN): Understanding gender characteristics of older driver accidents in West Midlands of United Kingdom. Safety Science 122.

[16] Huang, X., Zhang, M., Wang, J. \& Chen, J. (2018). Study on Law of Scenario Evolution Based on Accident Statistics of Hazardous Chemicals Transportation.In IEEE International Conference of Safety Produce Informatization (IICSPI), Chongqing, China (pp. 80-83). DOI: 10.1109/IICSPI.2018.8690521.

[17] Farooq, D. \& Moslem, S. (2019). A Fuzzy Dynamical Approach for Examining Driver Behavior Criteria Related to Road Safety. In Smart City Symposium Prague (SCSP), Prague, Czech Republic (pp. 1-7). DOI: 10.1109/SCSP.2019.8805741.

[18] Wu, J., Fan, W. y Wang, W. (2020). A Zero-Inflated Ordered Probit Model to Analyze Hazmat Truck Drivers' Violation Behavior and Associated Risk Factors. IEEE Access 8, 110974-110985. DOI: 10.1109/ACCESS.2020.3001165.

[19] Agustin, I.W. (2019). Traffic violation are mostly carried out by motorcyclist. In AIP Conference Proceedings 2202, 2019, 020118.

[20] Przepiorka, A.M., Hill, T., Blachnio, A.P., Sullman, J.M., Taylor, J.E. \& Mamcarz, P. (2020. Psychometric properties of the Driving Behaviour Scale (DBS) among polish drivers.

Transportation Research Part F: Traffic Psychology and Behaviour 73, 29-37.

[21] Tement, S., Plohl, N., Horva,t M., Musil, B., Jakus, G. \& Sodnik, J. (2020). Driving demands, stress reactivity and driving behavior: An interactional approach. Transportation Research Part F: Traffic Psychology and Behaviour 69, 80-90.

[22] Casselgren, J. \& Bodin, U. (2017). Reusable road condition information system for traffic safety and targeted maintenance. IET Intelligent Transport Systems 11(4), 230-238. DOI: 10.1049/iet-its.2016.0122.

[23] Hyodo, S., Yoshii, T., Satoshi, M. \& Hirotoshi, S. (2017). An analysis of the impact of driving time on the driver's behavior using probe car data. Transportation Research Procedia 21, 169-1790.

[24] Qiao, W. \& Shang, B. (2011). Current situation analysis and safety countermeasure study on road traffic accidents in China. In International Conference on Remote Sensing, Environment 
and Transportation Engineering, Nanjing (pp. 3034-3037). DOI: 10.1109/RSETE.2011.5964954.

[25] Selvathi, D., Pavithra, P. \& Preethi, T. (2017). Intelligent transportation system for accident prevention and detection. In International Conference on Intelligent Computing and Control Systems (ICICCS), Madrai (pp. 442-446). DOI: 10.1109/ICCONS.2017.8250761.

[26] Noland, R.B. \& Quddus, M.A. (2005). Congestion and safety: a spatial analysis of London. Transportation Research Part A 39, 737-754.

[27] Chen, L. \& Wang, P. (2017). Risk factor analysis of traffic accident for different age group based on adaptive boosting. In 4th International Conference on Transportation Information and Safety (ICTIS), Banff, AB (pp. 812-817). DOI: 10.1109/ICTIS.2017.8047861.

[28] Obaidat, M.T. \& Ramadan, T.M. (2012). Traffic accidents at hazardous locations of urban roads. Jordan Journal of Civil Engineering 6(4), 436-447.

[29] https://statystyka.policja.pl/st/ruch-drogowy/76562,wypadki-drogowe-raporty-roczne.html, (accessed on 08/10/2020).

[30] Polityka transportowa Państwa na lata 2006-2025 (State transport policy for 2006-2025), Ministerstwo Infrastruktury, Warszawa (2005), from http://archiwumukie.polskawue.gov.pl/HLP\%5Cfiles.nsf/0/6EDB2FBCDE37665EC1257266004241F6 / \$ plik / transport.pdf.

[31] Global Status Report on Road Safety 2019, World Health Organization 2018, from https://www.itf-oecd.org/sites/default/files/docs/irtad-road-safety-annual-report-2019.pdf.

[32] Frej, D.P., Zuska, A. \& Cadge, K. (2019). Analysis of vertical vibrations affecting a child transported in a child seat during a car passing over the release speed bump. The Archives of Automotive Engineering - Archiwum Motoryzacji 86(4), 111-125.

[33] http://www.stat.gov.pl (accessed on 08/10/2020).

[34] Vrábel, J., Sarkan, B. \& Vashisth, A. (2020). Change of driver's reaction time depending on the amount of alcohol consumed by the driver - the case study. The Archives of Automotive Engineering - Archiwum Motoryzacji 87(1), 47-56.

[35] Rybicka, I., Caban, J., Vrabel, J., Sarkan, B., Stopka, O. \& Misztal, W. (2018) Analysis of the Safety Systems Damage on the Example of a Suburban Transport Enterprise. In 11th International Scientific and Technical Conference on Automotive Safety, 18-20 April 2018, Casta-Papiernicka, Slovakia.

[36] Droździel, P. \& Wrona, R. (2018). Legal and Utility Problems of Accidents on Express Roads and Motorways. In 11th International Scientific and Technical Conference on Automotive Safety, 18-20 April 2018, Casta-Papiernicka, Slovakia. 